\title{
Liberalização, vulnerabilidade financeira e instabilidade: algumas considerações sobre a economia brasileira ${ }^{1}$
}

\author{
Adriana Moreira Amado ${ }^{2}$ \\ Paulo Rodrigo de Santana e Caruso ${ }^{3}$
}

\begin{abstract}
Resumo
$\mathrm{O}$ artigo analisa a economia brasileira e sua vulnerabilidade externa (no período recente) a partir do referencial teórico de Minsky (1982, 1982b e 1986). Observa-se a tendência recorrente de ampliação da vulnerabilidade e o movimento cíclico dessa tendência não associada a regimes cambiais específicos, mas ampliada pela falta de controles cambiais. Nota-se, também, que o aprofundamento da vulnerabilidade externa da economia brasileira deve-se, sobretudo, ao comportamento da conta financeira, que compensou, com sobras, os resultados positivos obtidos pela balança comercial. Tais elementos conduzem a observação de uma tendência à ampliação da instabilidade nas esferas financeira e real dessa economia.
\end{abstract}

Palavras-chave: Liberalização; Vulnerabilidade externa; Fluxo de capitais.

\begin{abstract}
Liberalization, financial vulnerability and instability: an analysis of the Brazilian economy

The paper analyses the Brazilian economy and its external vulnerability based on Minsky's theoretical approach. The continuous tendency increasing vulnerability and its cyclical movement, independent of the exchange rate regime, is observed. The paper points out that this tendency has been, in recent periods, mainly associated with the behaviour of the financial account, which compensated for the positive results of the country's balance of trade. All of these elements lead to the observation of an increased tendency towards increasing instability regarding the financial and real spheres of the Brazilian economy.
\end{abstract}

Keywords: Liberalization; External vulnerability; Capital flows.

JEL E42, F30, F41, E12, E32.

\section{Introdução}

A economia internacional na década de 1990 intensificou um processo já em curso de abertura e liberalização (seu início pode ser datado da década de 1960). Alguns países apresentaram formas de inserção na globalização mais ativas, outros optaram por atribuir aos mercados a determinação de suas variáveis essenciais, inserindo-se, assim, passivamente na economia mundial. A globalização apresentou-se como um processo rápido e intenso de queda das

(1) Trabalho recebido em 15 de outubro de 2008 e aprovado em 21 de novembro de 2010.

2 Professora do Departamento de Economia da Universidade de Brasília (UnB), Brasília, DF, Brasil. E-mail: uctpama@unb.br.

(3) Mestre em Economia pela Universidade de Brasília (UnB), Brasília, DF, Brasil. E-mail: prcaruso@yahoo.com.

Economia e Sociedade, Campinas, v. 20, n. 3 (43), p. 475-499, dez. 2011. 
barreiras externas dos mercados internacionais, tanto de mercadorias quanto de capitais, bem como um processo de dessegmentação e liberalização dos vários mercados nacionais, sobretudo, no que se refere à esfera financeira, permitindo a conexão dos vários mercados domésticos: câmbio, moeda, financeiro etc.. Os processos de globalização e liberalização estiveram associados a um ganho de importância da esfera financeira em detrimento da esfera real na lógica de acumulação de capital: financeirização da economia. Este último processo foi intensificado com a desregulamentação dos mercados financeiros domésticos e com a liberalização observada, na maioria dos países, no que se refere à conta financeira. A esfera financeira ganha, então, autonomia em relação à esfera real (Plihon, 1995; Chesnais, 1996, 1998, 2004; Epstein, 2005; Guttmann, 1996).

As causas e consequências dos processos não são nada consensuais entre os economistas. Por um lado, a perspectiva ortodoxa brinda os dois por representarem uma possibilidade de ampliação da esfera do mercado e, em decorrência disso, gerarem as condições para que os recursos sejam alocados de forma mais eficiente, alcançando o pleno emprego de forma mais rápida e segura. Por outro, os heterodoxos, ao mostrarem que o mercado não aloca de forma eficiente os recursos e pode, em decorrência de sua própria lógica de atuação, aprisionar a economia em situações de desemprego involuntário, apontam os problemas associados tanto à liberalização quanto à globalização. De acordo com o segundo grupo, esses dois processos poderiam não só aprofundar a tendência ao afastamento do ponto de demanda efetiva de seu nível de pleno emprego, como também poderiam ser ampliadas a instabilidade da economia internacional e das economias nacionais. Assim, a incerteza da economia seria aprofundada e maiores problemas associados ao emprego emergiriam.

No segundo grupo, cabe ressaltar as ideias de Minsky (1986). O autor parte da abordagem de Keynes (1936) das Economias Monetárias de Produção, também associadas ao paradigma de Wall Street e, sobre os elementos básicos desse conceito, constrói a hipótese de fragilidade financeira que demonstra o caráter eminentemente frágil e instável do ponto de vista financeiro do capitalismo. Ao tratar do real e monetário, como dois elementos intrinsecamente relacionados, o autor mostra a tendência à instabilidade real que esse sistema possui.

Nesse sentido, economias globalizadas e liberalizadas tenderiam a apresentar um nível de instabilidade maior o que acarretaria problemas associados ao produto de tais economias.

O trabalho objetiva exatamente a análise da vulnerabilidade externa de economias periféricas com o uso do Brasil como exemplo de uma economia periférica típica que se insere dentro da perspectiva liberal no processo de 
globalização. Para tanto, serão observados indicadores de sua vulnerabilidade externa com base nas análises de Minsky (1986). Após analisar a questão da vulnerabilidade externa da economia brasileira, serão tecidas algumas considerações sobre países com uma inserção mais ativa no processo de globalização, observando-se as possibilidades de resultados não congruentes entre os dois grupos.

A primeira seção define economias monetárias de produção e analisa o marco teórico mais amplo no qual a hipótese de fragilidade financeira de Minsky (1986) é gerada. Feito isso, na segunda seção, definem-se os principais elementos analíticos de Minsky, primeiro em economias fechadas e, posteriormente, estendendo a análise para economias abertas. Passa-se, então, para a análise da instabilidade gerada pela liberalização financeira em algumas economias periféricas na década de 1990 e, finalmente, nas duas últimas seções, a economia brasileira será analisada no período Pós-Real, mostrando que o referencial teórico minskyano apresenta-se bastante adequado para explicar a vulnerabilidade externa brasileira.

\section{Moeda e instabilidade}

Keynes e o marco teórico heterodoxo tendem a tratar as economias monetárias de produção e, portanto, as economias capitalistas contemporâneas dentro de um arcabouço que apenas permite a compreensão de suas trajetórias quando se observa o comportamento de variáveis reais e monetárias. A dicotomia clássica seria um caso para economias sujeitas ao paradigma da feira da aldeia, situação histórica essa que não se comprova historicamente ou, caso se comprove, não tem relevância para a análise de uma economia capitalista avançada (Keynes, 1973).

As economias monetárias de produção e a unicidade da esfera monetária e real que as caracterizam exigem a existência de um sistema financeiro desenvolvido e minimamente consolidado ${ }^{4}$. Isso permite que o investimento tornese independente da poupança e a mobilização ou comando de recurso, viabilizada pelo sistema financeiro, possa ocorrer de forma a que ele tenha lugar sem compromisso com a poupança e sua variação seja suficiente para gerar poupança correspondente. A decisão acerca do nível de investimento seria dada por meio da comparação entre eficiência marginal do capital e taxa de juros, esta última, uma variável monetária estabelecida pela demanda e oferta de moeda. Assim, aspectos monetários são elementos fundamentais para a trajetória de tais economias, uma vez que, em parte, definem o investimento e esta é a variável central para explicar o nível de produto e emprego da mesma. Ao ter, todavia, a variável fundamental

(4) Como observa Chick (1986). 
para a determinação do emprego e renda dessa economia centrada em dois componentes absolutamente instáveis e voláteis: taxa de juros e eficiência marginal do capital, aponta-se na direção de uma tendência inerente à instabilidade em economias monetárias de produção.

De acordo com Keynes (1936), aquelas teriam três características essenciais que explicariam tanto a instabilidade da demanda por moeda quanto (ambas são explicadas por Keynes) questões associadas à determinação da oferta de moeda e do papel que os bancos têm a desempenhar nas mesmas. Adicionalmente, também explicam a volatilidade da eficiência marginal do capital. Essas características são: tempo, incerteza e moeda.

Keynes (1936) observa: "Uma economia monetária de produção devemos crer que seja essencialmente aquela em que nossas perspectivas diversas de futuro são capazes de influenciar a quantidade e não meramente a alocação do emprego" (p. xxii).

É gerada uma necessidade de refletir sobre o papel central da noção de tempo e expectativas em seu arcabouço teórico.

O tempo, nesse contexto, está imbuído de seu atributo essencial de irreversibilidade, o que o separa de forma definitiva da noção de espaço em que a bidirecionalidade é possível. A irreversebilidade do tempo gera problemas ao conhecimento, portanto faz das expectativas elementos que são gerados em um contexto eminentemente não ergódico.

Nesse sentido, a incerteza associada ao tempo histórico a qual se contrapõe à perspectiva neoclássica, aqui observada como risco, pode ser descrita como aquela não sujeita a distribuições de probabilidade (Knight, 1933).

Para agir em um ambiente sujeito ao tempo histórico e incerteza e evitar a paralisia esperada dentro desse contexto, os agentes têm de gerar mecanismos que permitam a formação de expectativas e, por meio delas, a tomada de decisão. Keynes (1936) pontua as convenções como um elemento fundamental para balizar o processo de formação de expectativas e consequente ação dos indivíduos, chamando atenção ao mesmo tempo para a existência de animal spirits que empurram os agentes para a ação, ao invés do imobilismo.

Expectativas formadas em tal âmbito tendem a garantir o mínimo de estabilidade e possibilidade decisória aos agentes em um contexto de incerteza. Ao terem caráter subjetivo e convencional forte, todavia, estão sujeitas a movimentos violentos, o que tende a provocar instabilidade quando nelas há mudanças. Isso torna o ambiente econômico bastante volátil, o que reforça o caráter convencional do processo decisório (Keynes, 1936, 1937). 
Assim sendo, é fundamental a existência de mecanismos sociais, permitindo que os agentes lidem com a incerteza. É o ponto em que surge a moeda, padrão de liquidez para a economia. Ela dá aos agentes a flexibilidade necessária e desejada para não ficar em posição imobilizada na economia. Quando permite, porém, essa flexibilidade, esteriliza parte da demanda da economia. Ação que, normalmente, está associada ao impacto do aumento da demanda de moeda sobre a taxa de juros e desta, sobre o investimento. Destarte, dão-se as bases para a não neutralidade da moeda.

Então, a especulação sobre o movimento da taxa de juros (motivo especulação) e a reação dos agentes à incerteza (motivo precaução) conduzem ao surgimento da preferência pela liquidez e esta cria as condições para a determinação conjunta (esfera real e monetária) da trajetória de crescimento da economia.

\section{Minsky e a instabilidade inerente às economias monetárias de produção}

A dissociação entre oferta e demanda por moeda é artificial e algo problemática, pois a própria existência de uma demanda por moeda instável inviabiliza a exogeneidade da oferta de moeda ${ }^{5}$. Se as razões, portanto, para que a demanda de moeda seja instável estão dadas, é necessário discutir a oferta monetária e o papel dos bancos na mesma, de forma mais detalhada. É exatamente o que faz Minsky (1982), ao buscar no comportamento dos bancos, como importantes determinantes da oferta de moeda, a origem das flutuações econômicas em economias monetárias de produção (Mollo, 1988).

Assim, os bancos têm seu comportamento regido por elementos semelhantes aos das demais firmas em seu comportamento maximizador e na disputa por mercados. A "mercadoria" por eles produzida, entretanto, é de natureza bastante específica, o que lhes confere um papel central no sistema econômico. Faz com que a forma como se dá o financiamento nas economias monetárias de produção seja o elemento chave para entender a instabilidade geral dele, uma vez que o financiamento é um elemento muito relevante para explicar o investimento que, em última instância, determina o nível de emprego da economia.

Stable growth is inconsistent with the manner in which investment is determined in an economy in which debt-financed owner-ship of capital assets exists, and the extent to which such debt financing can be carried is market determined. It follows that the fundamental instability of a capitalist economy is upward. The tendency to transform doing well into a speculative investment boom is the basic instability in a capitalist economy (Minsky, 1982, p. 66)

(5) Ver Dow (1982) e Chick (1986). 
A instabilidade financeira está associada por um lado à maneira como os agentes econômicos e os bancos formam suas expectativas em um contexto de incerteza. Nesse caso, as expectativas são formadas com base, em grande medida, em convenções sujeitas a movimentos bruscos e fenômenos de natureza psicológica que também são bastante voláteis. Em contrapartida, a disputa por mercado faz os bancos expandirem o crédito em momentos de expectativas favoráveis, consequentemente, financiarem firmas com um perfil cada vez mais vulnerável, fragilizando, portanto, a economia como um todo inclusive o próprio sistema financeiro (Mollo, 1988).

O próprio crescimento causa instabilidade por gerar uma fragilidade financeira maior. Minsky (1982) classifica as unidades econômicas de acordo com seu perfil de prudência em:

Hedge finance takes place when the cash flows from operations are expected to be large enough to meet the payment commitments on debts. Speculative finance takes place when the cash flow from operations are not expected to be large enough to meet payment commitments, even though the present value of expected cash receipts is greater than the present value of payment commitments. Speculating units expect to fulfill obligations by raising funds by new debts. ... In addition to hedge and speculative finance there is Ponzi finance - a situation in which cash payments commitments on debt are met by increasing the amount of debt outstanding. High and rising interest rates can force hedge financing units into speculative financing and speculative financing units into Ponzi financing. Ponzi financing units cannot carry on too long. Feedbacks from revealed financial weakness of some units affect the willingness of bankers and businessmen to debt finance a wide variety of organizations. Unless offset by government spending, the decline in investment that follows from a reluctance to finance leads to a decline in profits and in the ability to sustain debt. Quite suddenly a panic can develop as pressure to lower debt rations increases (p. 67).

A maior participação de firmas financeiramente frágeis no mercado torna a economia como um todo mais vulnerável a rompimentos no padrão de financiamento dos bancos que lhes dão lastro. Na fase ascendente do ciclo em que as expectativas são favoráveis, haveria uma tendência ao ganho de participação das firmas especulativas e Ponzi na economia e quando, em momentos de reversão de expectativas, os refinanciamentos fossem cortados, elas seriam inviabilizadas e a crise de seus mercados, espalhados por toda a economia.

Assim, a natureza endógena da oferta de moeda em economias monetárias de produção e a incerteza que leva à formação de expectativas com base em convenções e elementos bastante subjetivos conduzem a economia a movimentos cíclicos que lhe amplificam a instabilidade e fragilidade, com impactos significativos em sua esfera real. Os ciclos estariam, assim, intrinsecamente associados à esfera financeira da economia. 
Essa perspectiva que foi desenvolvida pensando-se em economias fechadas, poderá facilmente ser estendida a economias abertas. Países serão tratados como unidades econômicas e classificados como Hedge, Especulativos e Ponzi (caracterização feita por Minsky (1982) das unidades econômicas de acordo com seu grau de vulnerabilidade financeira). O referencial teórico de Minsky (1982) foi desenvolvido fundamentalmente para economias fechadas. Trabalhos diversos, porém, procuraram usar o arcabouço teórico de Minsky para tratar as crises financeiras internacionais recentes. Citam-se Arestis e Glickman (2002); de Paula e Alves Jr. (2000); Lopez (1997); Resende e Amado (2007). Eles mostram que as conclusões de Minsky não apenas são válidas para essas economias, como também tendem a ampliar-se com a abertura financeira. São trabalhos que apresentam medidas de vulnerabilidade externa, mostram seu comportamento em uma determinada fase do ciclo e o que ocorre em crises específicas. Aqui, apresentam-se elementos associados à fragilidade financeira da economia brasileira em dois momentos distintos: câmbio fixo e câmbio flutuante, mas em ambos os casos, dentro de um arcabouço de políticas de caráter liberal, observa-se como a economia evolui em termos de sua vulnerabilidade externa ao longo do ciclo de liquidez internacional, chegando a um padrão cíclico da mesma na década de 1990 e 2000.

O próprio Minsky (1994) aborda a questão da crescente integração financeira em nível mundial, mostrando que ela produz um aumento da instabilidade econômica. De acordo com o autor, o processo de globalização não apenas teve impactos reais ligados ao comércio, mas esteve, sobretudo, associado à remoção de barreiras à movimentação e diversificação internacional de portfólios. Paralelo ao aumento das posições assumidas em moeda estrangeira surgiu também a demanda por instrumentos capazes de limitar as perdas em caso de variações bruscas nas taxas de câmbio, e.g., instrumentos derivativos tais como swaps e futuros. Essa demanda por proteção contra flutuações cambiais era desnecessária na época do padrão-ouro e mesmo no período do pós-guerra, quando o acordo de Bretton Woods ainda conseguia manter as taxas de câmbio amplamente estabilizadas, visto que as demais moedas eram cotadas perante o dólar norte-americano o qual garantia uma paridade fixa com o ouro. A partir de 1971, todavia, com o rompimento desse acordo e a posterior vigência da livre flutuação cambial, o cenário mudou substancialmente ${ }^{6}$.

Ao trazer a análise do novo cenário que surgiu após o colapso de Bretton Woods ao contexto das economias periféricas, Prates (2005) observa a

(6) Com a intensificação das pressões sobre a moeda norte-americana, em agosto de 1971, Nixon unilateralmente suspendeu a conversibilidade do dólar em ouro a uma taxa fixa, rompendo o compromisso assumido em 1944, quando da assinatura do acordo de Bretton Woods. Esforços tendentes a restaurar o equilíbrio com base em novas paridades fracassaram e, desde 1973, o sistema de flutuações fixas, mas ajustáveis, foi substituído por um de flutuação suja (Belluzo, 1995). 
vulnerabilidade de tais economias decorrente das assimetrias monetária e financeira inerentes ao novo paradigma de livre flutuação cambial e maior flexibilização nos movimentos de capitais.

As assimetrias monetárias, segundo Prates (2005), estariam associadas ao sistema de hierarquia em que a moeda plenamente conversível ocuparia o topo e seria representada pelo Dólar Americano, desempenhando todas as funções da moeda tanto em nível nacional quanto internacional. A partir dela, viriam as demais também posicionadas em uma estrutura hierárquica, associadas às funções que as moedas conseguem desempenhar na economia internacional. Nesse sistema, as periféricas estariam no final da escala por causa da parcialidade de suas funções, o que lhes retira conversibilidade. Ao mesmo tempo, as economias detentoras das moedas inconversíveis perdem graus de independência em sua política monetária, exatamente, por terem de se subordinar às políticas monetárias dos países que possuem moedas conversíveis. Ao lado dessas questões, vem o problema da impossibilidade de emitir dívida externa na própria moeda, o que compromete ainda mais a liberdade de política monetária e financeira desses países. No contexto e em função da fragilidade monetária internacional dos países periféricos, ficam subordinados em suas necessidades de financiamento ao "volume e direção" dos fluxos financeiros internacionais que lhes são determinados exogenamente. Em situação de maior volatilidade associada ao próprio processo de liberalização, acentuam-se a instabilidade e vulnerabilidade das economias periféricas.

\section{A liberalização da conta financeira e seus impactos sobre a instabilidade financeira na periferia}

Com o objetivo de mostrar maior instabilidade financeira à qual a economia internacional está sujeita, dado o cenário de globalização e liberalização, Arestis e Glickman (2002) fazem a extensão para a economia aberta da hipótese de fragilidade financeira de Minsky (1982b). Argumentam que o extenso processo de liberalização financeira transcorrido no leste asiático foi determinante para o agravamento da crise financeira que assolou aquela região do globo na segunda metade da década de 1990. A queda das barreiras ao movimento de capitais nas décadas de 1980 e 1990 explica, em boa medida, o ocorrido nas cinco economias da região que mais sofreram com a reversão dos fluxos de capitais: Indonésia, Coreia do Sul, Malásia, Filipinas e Tailândia. Esse processo de liberalização abriu caminho para os bancos locais envolverem-se em arriscadas operações de empréstimo doméstico e aumentarem suas captações externas consideravelmente. Empresas nacionais também foram estimuladas a contraírem dívida externa e, em tal ambiente de euforia, o nível de alavancagem financeira igualmente se expandiu (Arestis; Glickman, 2002). 
Entre 1996 e 1997, o ingresso líquido de capital externo foi da ordem de US\$ 109 bilhões, representando 11\% do PIB agregado dessas cinco economias no imediato período pré-crise (Kregel, 1998).

Tais recursos foram amplamente canalizados para o setor imobiliário que absorveu de $25 \%$ a $40 \%$ dos empréstimos bancários na Tailândia, Malásia e Filipinas em 1998, tendo como base o crédito externo de curto prazo (Unctad, 1998).

As firmas asiáticas, repentinamente, descobriram que seria possível obter funding externo à metade do custo de captação interno. Como resultante, houve um vasto fluxo de capital que inflou as reservas bancárias domésticas e provocou um boom no crédito local. O endividamento externo contraído foi fortemente viesado para o curto prazo, contribuindo para a elevação da fragilidade externa nos termos propostos por Minsky (1982b), ou seja, a economia foi movendo-se de uma posição hedge para speculative em função de forças endógenas ao próprio sistema. Quando a crise veio à tona, em 1997, o setor imobiliário sentiu fortemente seus efeitos, assim como outros setores que se envolveram em atividades arriscadas de caráter especulativo, no sentido de Minsky (1986). Isso pôde ser evidenciado pelo aumento da exposição em moeda estrangeira, ao passo que o governo, nesses países, removeu ou afrouxou os controles nas captações externas privadas, abandonou o direcionamento dos empréstimos e investimentos e resistiu a recomendações para fortalecer a supervisão bancária.

$\mathrm{Na}$ ótica minskiana da crise, o período de sucesso e euforia econômica no leste asiático conduziu a um afrouxamento nos controles das práticas financeiras na região, estimulado complementarmente pelo cenário de liberalização nos fluxos de capitais. Foi defendido pelo mainstream econômico desde o colapso de Bretton Woods e posto em prática de maneira substancial naquela região. Ao sustentar uma estrutura de passivos de curto prazo, financiando projetos de longa maturação, essas economias estavam caminhando no sentido speculative movidas por forças inerentes ao próprio sistema capitalista que, em períodos prolongados de otimismo, apresenta tal comportamento. Ainda mais, ao persistir nesse modelo, agora com o passivo fortemente denominado em moeda conversível enquanto o ativo permanece em moeda local, a estrutura financeira encontra-se duplamente comprometida, caracterizando a extensão do modelo de fragilidade financeira de Minsky (1986) para a economia aberta.

Em linha de raciocínio semelhante, López (1997) analisou o caso da crise mexicana de 1994. Em primeiro momento, houve amplo processo de liberalização econômica e financeira no transcorrer da segunda metade da década de 1980 e início dos anos 1990. No campo comercial, vale destacar a abertura efetuada no comércio exterior, abarcando redução de tarifas e eliminação de barreiras não tarifárias, tudo isso associado à adesão do México ao Gatt, em 1986 e, ao Nafta, 
em 1993. Paralelamente, no lado financeiro, houve amplo processo de liberalização e desregulamentação. Com mais destaque, reservas compulsórias foram eliminadas, taxas de juros, liberadas, os bancos, autorizados a tomar empréstimos externos sem restrição e os não residentes, autorizados a investir em ativos financeiros doméstico praticamente, sem impedimentos.

A experiência mexicana de liberalização, entretanto, não trouxe consigo um surto de crescimento no investimento estrangeiro direto, mas atraiu de fato um vasto fluxo de recursos financeiros em portfólio. A desregulamentação do setor financeiro doméstico deu aos bancos maior margem de manobra na administração de seus ativos e passivos, além de novas oportunidades para reduzir os requerimentos de reservas bancárias e inovar com novos instrumentos financeiros. No sentido minskiano, essas práticas elevaram a fragilidade financeira mexicana, deslocando a economia para a uma posição menos hedge e mais speculative.

Muito embora o processo de liberalização e desregulamentação financeira tenha de fato estimulado tanto o consumo quanto o investimento doméstico, houve também um movimento paralelo de apreciação cambial, dado o nível de juros mais elevado na economia mexicana e o arcabouço de livre mobilidade de capitais. Isso ocasionou uma perda de competitividade para a produção doméstica e, assim, as exportações não lograram alcançar um substancial patamar mais elevado ao passo que as importações aumentaram progressivamente. Conduziu-se, por fim, a economia a uma deterioração nas transações correntes até atingir um déficit superior a 7\% do PIB em 1994. A crise foi, portanto, a consequência de uma estratégia falha: o governo promoveu reformas institucionais e tomou medidas que levaram à recuperação econômica no primeiro momento, mas provocaram um desequilíbrio externo desde o princípio. Desequilíbrio esse que elevou a fragilidade externa da economia mexicana de tal forma que a crise de dezembro de 1994 tornou-se o desfecho inevitável da política econômica adotada (López, 1997).

\section{A economia brasileira e 0 índice de fragilidade externa}

Em relação à economia brasileira, Paula e Alves (2000) fazem uma leitura de sua fragilidade externa, no sentido proposto por Minsky (1982b), para o período que compreende a primeira fase do Plano Real (1994-1999) ${ }^{7}$. Essa fase abrange o período em que o plano de estabilização esteve calcado na política cambial e a moeda norte-americana, após uma desvalorização inicial, passou a flutuar dentro de um sistema de bandas cambiais que, na prática, operava quase

(7) Aqui, trata-se o Plano Real como se possuísse duas fases. Esse corte é um tanto arbitrário, pois grande parte de seus pilares foi mantida ao longo de todo o período analisado. O que levou, contudo, a caracterizá-lo em duas fases foi mudança do regime cambial. Assim, a primeira fase é o período do regime cambial com base em bandas cambiais e a segunda, a de câmbio flutuante. 
como um câmbio fixo ${ }^{8}$. A política monetária foi, também, restritiva. Os supracitados autores argumentam que um plano de estabilização com âncora cambial só será sustentável enquanto houver fluxo de capital disposto a financiar o déficit em conta-corrente derivada da valorização cambial. Para mensurar, então, a fragilidade externa da economia brasileira, eles elaboraram o external fragility index (EFI) que, basicamente, mede a razão entre o passivo externo mais imediato da economia (potencial e efetivo) e os recursos disponíveis para fazer diante de tais compromissos.

Como observado anteriormente, Minsky (1986) desenvolveu o conceito de fragilidade financeira como sendo a capacidade de uma economia de lidar com restrições em sua condição de financiamento sem provocar uma desorganização generalizada nos fluxos de pagamentos entre os agentes econômicos. Uma aceleração na taxa de crescimento do produto levou as firmas a, gradativamente, tornarem-se endividadas a fim de expandirem a produção. Já, o setor bancário tendeu a acomodar a crescente demanda por crédito e, o processo alicerçado em fatores inerentes ao sistema capitalista de produção, fez a economia caminhar de uma posição inicial hedge para outra speculative e, no limite, Ponzi. As flutuações cíclicas da economia resultaram da forma como as firmas financiavam seus portfólios, com a fragilidade financeira elevando-se em períodos de crescimento econômico devido à atividade dos agentes especulativos. Minsky (1982b) percebeu que a decisão de investir caminhava pari passu com a escolha dos meios de financiamento. Ambas as decisões definiram a extensão do grau de vulnerabilidade da economia a alterações adversas no cenário macroeconômico.

Retomando o EFI, dadas as informações do balanço de pagamentos de um país, é possível saber qual seu grau de fragilidade financeira externa. Para tanto, faz-se uma mensuração de quão necessário é recorrer ao mercado internacional de capitais a fim de serem renegociadas posições financeiras em aberto, por não poderem ser honradas de imediato. Nesse sentido, o EFI relaciona-se com a capacidade de a economia quitar seus compromissos externos no vencimento, ou seja, o índice compara o passivo externo de curto prazo, efetivo e potencial, com a capacidade de pagamento mais imediata:

$(31)$ EFI $=(\mathbf{M}+\mathbf{D i}+$ Dos $+\mathbf{A}+\mathbf{S T C}-1+$ NIP-1 $) /(\mathbf{X}+\mathbf{R i}+\mathbf{R o s}+\mathbf{R E}-1+\text { FDI }+ \text { Lml })^{9}$

(8) Paula e Alves (2000) fazem um relato bastante abrangente dessa primeira fase do Plano Real.

(9) em que: $\mathbf{M}=$ importações; $\mathbf{X}=$ exportações; $\mathbf{D}=$ despesa com juros (i) e outros serviços; $\mathbf{R}=$ receita de juros (i) e outros serviços; $\mathbf{A}=$ amortização de empréstimos; $\mathbf{S T C}-\mathbf{1}$ = estoque de capital de curto prazo com um trimestre de defasagem; NIP-1 = estoque de investimento líquido em portfólio com um trimestre de defasagem; RE-1 = nível de reservas oficiais internacionais no último dia do trimestre anterior; FDI = fluxo de entrada correspondente aos investimentos estrangeiros diretos; $\mathbf{L m l}=$ empréstimos de médio e longo prazo. Buscou-se ser o mais fiel ao índice e variáveis estabelecidas por Paula e Alves Jr (2000) para permitir comparações entre os dois índices. 
As obrigações efetivas de pagamentos compreendem as despesas com importações (M), juros (Di) e outros serviços (Dos), além das amortizações de empréstimos (A). Já, as obrigações potenciais são representadas pelo estoque de capital de curto prazo (STC-1) e de investimento líquido em portfólio (NIP-1), ambos com um trimestre de defasagem e agregados desde o primeiro trimestre de $1991^{10}$. Essas variáveis perfazem os passivos mais representativos (efetivo e potencial) dentro da estrutura de balanço de pagamentos de uma economia. Passivos que podem ser cobertos por meio das receitas de exportação $(\mathbf{X})$, outros serviços (Ros), empréstimos de médio e longo prazo (Lml) e investimento estrangeiro direto (FDI) além da posição das reservas ao final do trimestre anterior (RE-1).

Desse modo, quanto mais alto o valor do índice, maior é a propensão da economia a ser afetada por uma mudança súbita no cenário externo, tal como uma elevação da taxa de juros no país emissor da moeda-chave. Visto de outra forma, quanto maior o índice, menor é a capacidade de esse país honrar seus passivos imediatos, tornando-se mais dependente de refinanciamento externo e do uso de suas reservas. Alternativamente, quanto menor o índice, maior é a capacidade de o país honrar seus compromissos financeiros de curto prazo com recursos próprios, i.e, sem necessidade de recorrer ao mercado internacional de capitais. Tal interpretação possibilita classificar a postura financeira de um país de uma maneira análoga à desenvolvida por Minsky (1982b) em sua hipótese de fragilidade financeira. Quando o EFI cai, os passivos efetivos e potenciais de curto prazo são cobertos por receitas correntes e fontes de financiamento de médio e longo prazo de tal forma que a economia, como um todo, encontra-se em situação mais hedge. Por outro lado, quando o EFI sobe, ela se torna bastante vulnerável, tendendo a depender cada vez mais do humor do mercado financeiro internacional para refinanciar seus vencimentos de curto prazo, impossíveis de serem pagos com recursos próprios. Em outros termos, a economia encontra-se em posição mais speculative $^{11}$. Ao fazerem a análise da economia brasileira durante a primeira fase do Plano Real à luz do EFI, Paula e Alves (2000) destacam que o estoque de capital de curto prazo e o investimento líquido em portfólio começaram a

(10) Paula e Alves (2000), para o cálculo do EFI, utilizam dados de capital de curto prazo e investimento em portfólio com um trimestre de defasagem, pois entendem que esses passivos só podem ter vencimento a partir do trimestre subsequente ao influxo. O mesmo tratamento foi dado às reservas internacionais, posto que os passivos de cada trimestre serão cobertos com receitas externas do trimestre citado, somadas às reservas verificadas ao final do trimestre anterior. Esses elementos foram mantidos para garantir a compatibilidade do indicador elaborado por aqueles autores e o indicador, calculado no presente trabalho.

(11) Studart (2005) alerta para o problema crônico de carência de financiamento de longo prazo nos países da periferia em geral e no Brasil em particular, em oposição à situação dos países de centro, que contam com um mercado financeiro bastante desenvolvido e com vasta oferta de financiamento privado de longo prazo. No Brasil, o acesso restrito a esse crédito dá-se, em geral, por meio de atuação do Estado, como no caso do Banco Nacional de Desenvolvimento Econômico e Social (BNDES). 
aumentar no início de 1993, resultantes de diferentes fatores tais como a remoção de controles na conta financeira, o diferencial entre as taxas de juros doméstica e externa e a maior diversificação entre os investidores institucionais internacionais. Eles ressaltam a correlação positiva existente entre o estoque de capitais de curto prazo e em portfólio e o EFI. Isso se deve ao fato de que, quanto mais elevado for o estoque, maior será o potencial de saída de capitais em momentos de reversão das expectativas por parte dos agentes econômicos, refletindo, assim, na elevação da fragilidade externa.

Com o início do plano, a contínua atração de capitais de curto prazo em função do diferencial de juros e alta liquidez internacional, aliada à deterioração do saldo comercial em razão do câmbio sobrevalorizado, ocasionou a elevação da fragilidade externa da economia brasileira até o pico verificado em 1997, quando do desfecho da crise asiática iniciada em outubro. Naquele momento, o efeito contágio provocado pela crise desencadeou fuga de capitais na periferia, o que se traduziu em gradual retração do EFI. As economias periféricas tendem a seguir e absorver a disposição do sistema financeiro internacional em estender empréstimos e aceitar financiar projetos sujeitos a uma vulnerabilidade maior. Consequentemente, isso causa ciclos reflexos nas economias cujo desenvolvimento está condicionado aos ciclos de liquidez internacional (Resende; Amado, 2007).

Quando muda essa percepção otimista por parte dos provedores de liquidez internacional, o fluxo financeiro inverte o sentido, proporcionando todas as condições para a emergência de uma crise financeira na periferia, com repercussões no setor real da economia. Assim foi no período 1997-1999, com o desencadeamento de seguidas crises nos países emergentes, iniciando-se pelo leste asiático.

Sob tal aspecto, vale uma ressalva apontada por Paula e Alves Jr. (2000). Em períodos de normalidade, o comportamento do EFI retrata maior ou menor vulnerabilidade externa de uma economia. Já, em momentos de crise como ocorrido em 1997, a fuga de capitais e a consequente redução do estoque de capitais de curto prazo e em portfólio, acarretam em redução do EFI, o que pode transmitir a equivocada impressão de a economia estar mais sólida. Nesse contexto, o EFI deverá ser interpretado diferentemente no sentido de que durante uma crise cambial a tendência descendente do índice evidencia uma situação externa crítica causada por fuga de capitais e deterioração das reservas internacionais.

O ataque especulativo contra o real iniciado em outubro de 1997 forçou uma pronta resposta por parte do governo, forçado a vender parte de suas reservas internacionais que caíram de US\$ 61,2 bilhões, em setembro, para US\$ 51,4 bilhões, em dezembro. Além disso, no esforço para salvar a moeda, a taxa de juros 
básica para a economia, Selic, foi elevada de $21 \%$ para $44 \%$ a.a. e o Banco Central passou a ofertar títulos públicos com cláusula cambial, na tentativa de oferecer hedge ao mercado e arrefecer a demanda por dólares que pressionava o câmbio naquele momento. O ano de 1998 igualmente foi marcado por vulnerabilidade na esfera macroeconômica e, com o desencadear da crise russa, em outubro e novembro, o governo viu-se instado a novamente promover uma elevação dos juros básicos, tentando conter o processo especulativo em andamento. A taxa Selic foi elevada para $42,2 \%$ a.a. e, por fim, o Brasil celebrou um acordo de assistência financeira junto ao FMI, no valor total de US\$ 41 bilhões. Em janeiro de 1999, em que pese todos os esforços empreendidos na tentativa de preservar o valor da moeda, a situação tornara-se insustentável. Após forte desvalorização inicial, o real passou doravante a operar oficialmente, sob um regime de livre flutuação, muito embora, na prática, verifica-se uma flutuação suja ${ }^{12}$.

\section{Uma extensão do Índice de Fragilidade Externa para a segunda fase do Plano Real}

Nesta seção, estender-se-á o EFI para o período 1999-2009 a fim de verificar-se como está a vulnerabilidade externa da economia brasileira na segunda fase do Plano Real, o período de câmbio flutuante. O Gráfico 1 mostra o comportamento do índice para todo o período - as duas fases do Plano Real - e o Gráfico 2 retrata o estoque de investimento líquido em portfólio e capitais de curto prazo.

Gráfico1

Índice de Fragilidade Externa (EFI) da economia brasileira: 1993-2009

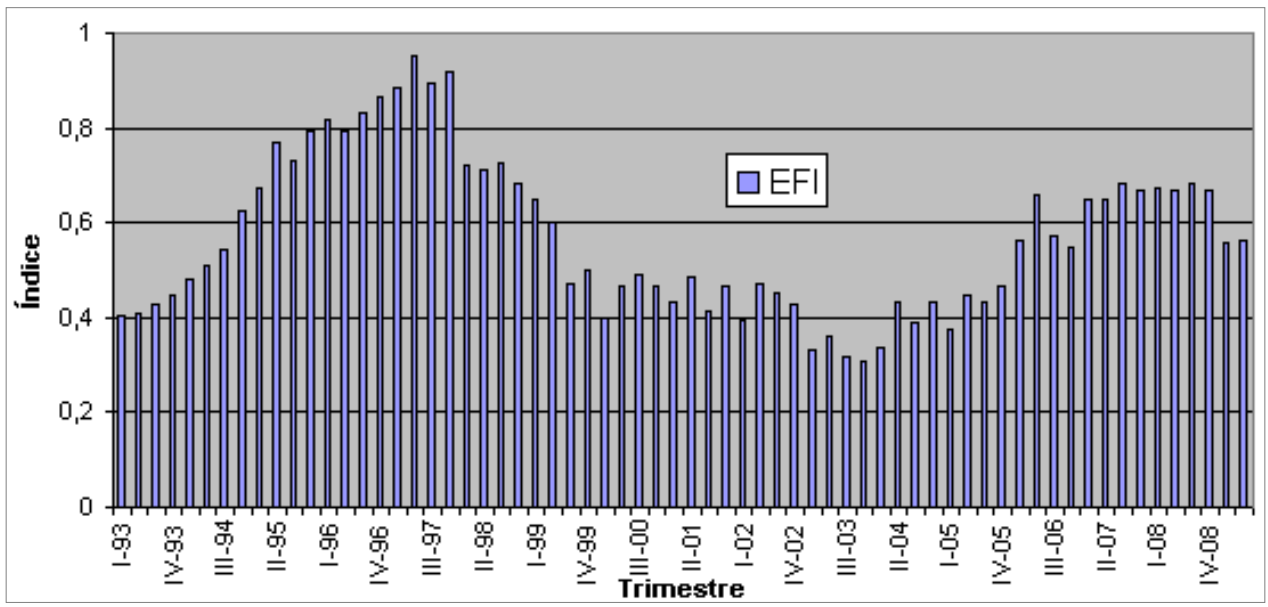

Fonte: Banco Central do Brasil - Séries Temporais.

(12) Paula e Alves (2000) fazem uma análise bastante pormenorizada dos fatos econômicos que marcaram a primeira fase do Plano Real, relacionando-os com o índice de fragilidade externa - EFI. 
Liberalização, vulnerabilidade financeira e instabilidade: algumas considerações sobre a economia brasileira

Gráfico 2

Investimento em portfólio e capital de curto prazo no Brasil: 1993-2009

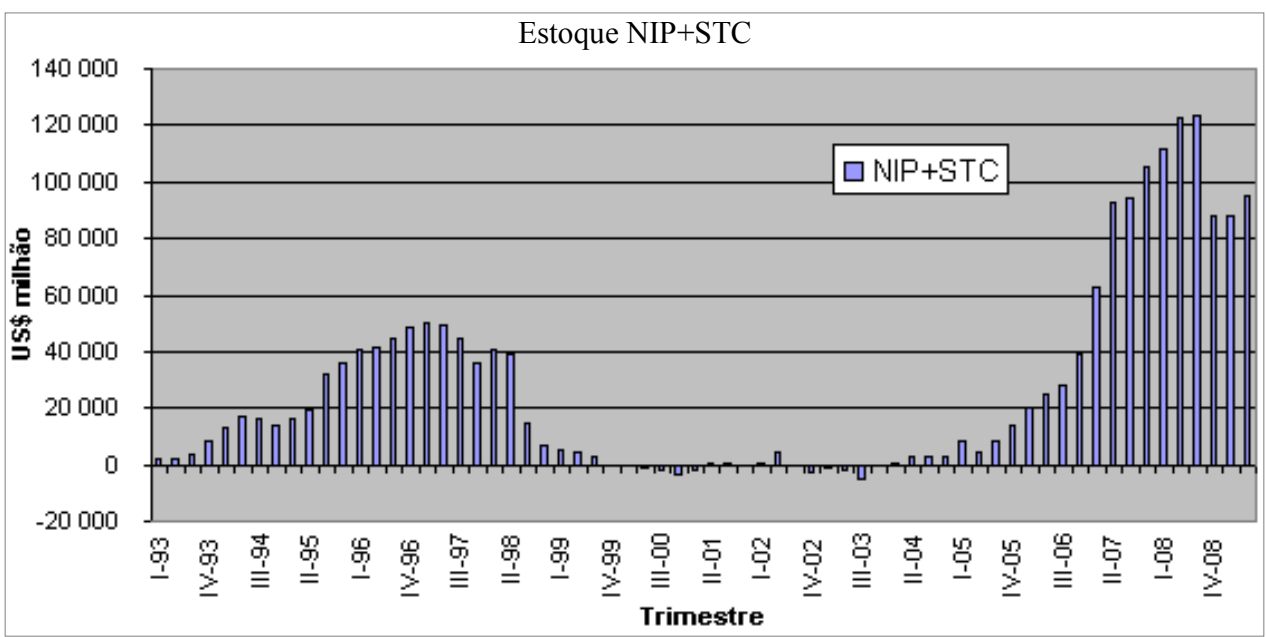

Fonte: Banco Central do Brasil - Séries Temporais.

De imediato, percebe-se a drástica redução no estoque de portfólio e capitais de curto prazo, ocorrida entre 1997 e 1999, em decorrência das crises asiática (1997), russa (1998) e brasileira (1999), culminando na livre flutuação da moeda a partir de janeiro. Desde então, tal estoque tem-se comportado de maneira oscilante até o primeiro trimestre de 2004, quando começa novamente a se avolumar. Em decorrência disso, o EFI, após um arrefecimento no momento de crise, provocado pela vultosa fuga de capitais, passa mais uma vez a exibir tendência ascensionista a partir de 2004, embora ainda não tenha alcançado o nível auferido no momento pré-crise de 1997. Isso, porém, não deixa de ser um fator de preocupação, visto que no espírito da hipótese de fragilidade financeira de Minsky (1982b), a economia brasileira está caminhando em sentido mais speculative. Nos últimos três anos citados, o EFI tem-se mantido, grosso modo, no mesmo patamar, apesar da crise financeira desencadeada pelo mercado hipotecário norte-americano em 2008. Tal fato ocorreu porque, muito embora o nível de investimento em portfólio aumentara bastante nos últimos anos, um fator de agravamento da fragilidade, por outro lado, as reservas internacionais também cresceram na mesma proporção, um fator de atenuação da fragilidade externa.

Com efeito, a extensão do EFI mostra o caráter cíclico minskiano presente na análise feita por Paula e Alves (2000). Após o boom da primeira fase do plano, motivado pela euforia nos mercados centrais e sua maior propensão a correr riscos, veio, em seguida, o momento de frustração e a subsequente contração da liquidez internacional aos países periféricos. Observa-se, não obstante, a partir de 2004, a retomada do processo e o início de um novo ciclo. Ademais, percebe-se que a mudança de regime cambial verificada em 1999 não invalida esse 
movimento cíclico. Em verdade, os fluxos de capital em direção aos países da periferia estão muito mais atrelados a uma dinâmica exógena a essas economias. Estão, de fato, condicionados às decisões de política monetária do país emissor da moeda-chave, bem como dos demais países centrais (Prates, 2005).

Bahry e Porcile (2004) retratam a recorrência dos ciclos de endividamento minskiano na economia brasileira, para o período 1968-1999. Em geral, foram identificados ciclos em que um rápido processo de endividamento, ancorado no setor externo, foi seguido de uma situação de crescente fragilidade minskiana, com a consequente queda das taxas de crescimento. Assim, foi a conduta do milagre econômico nos períodos de 1968 a 1973 e do segundo Plano Nacional de Desenvolvimento - PND (1974-1976). Após o conturbado período de ajustamento recessivo da década de 1980, frente à nova realidade de fechamento do mercado financeiro internacional para a economia brasileira, na década de 1990, tem-se o retorno da elevada liquidez internacional, viabilizando novo ciclo de expansão na América Latina.

Em linhas gerais, as duas fases do Plano Real podem ser diferenciadas da seguinte forma: a primeira (1994-1999), objeto do estudo de Paula e Alves, foi essencialmente caracterizada por âncora cambial, crescente dependência do financiamento externo e déficit fiscal. A segunda (1999 em diante) tem sido marcada por câmbio flutuante, substancial melhora do saldo em transações correntes e forte ajuste fiscal. Como contrapartida do acordo assinado com o FMI no bojo da crise de 1998, que veio resultar na livre flutuação cambial em janeiro de 1999, o governo comprometeu-se a perseguir rígidas metas de ajuste fiscal. Metas essas que, entre outras medidas, traduziram-se na aprovação da Lei de Responsabilidade Fiscal (LRF) e nas reiteradas tentativas de reforma da previdência.

A forte desvalorização do real ocorrida em janeiro de 1999, quando a taxa de câmbio passou de R\$/US\$ 1,20 para mais de R \$US\$ 2,00 em menos de 45 dias, contribuiu de forma decisiva para o movimento de reversão nas transações correntes que se verificou na economia brasileira. Em função de uma contração das importações em um primeiro momento e, posteriormente, também de um progressivo aumento das exportações, o Brasil saiu de uma posição deficitária na balança comercial e passou a obter saldo comercial positivo e crescente a partir de 2001. No esforço, todavia, para controlar o repasse da desvalorização cambial para o nível de preços (pass-through), a equipe econômica promoveu, simultaneamente, um rígido aperto monetário. A taxa de juros básica real, portanto descontada a inflação, manteve-se no patamar de 15\% a.a. em 1999, operando dentro no novo modelo de metas de inflação que havia sido introduzido pelo Banco Central a partir da livre flutuação cambial do Boletim Análise do Mercado de Câmbio (BCB) em 1999, 2000 e 2001. Em que pese esse descompasso entre o 
nível de juros interno e externo, por conseguinte propiciando oportunidades de ganho de arbitragem, ainda pairava grande incerteza quanto ao rumo que o câmbio flutuante iria tomar no curto e médio prazo. Além disso, o ano de 2001 foi particularmente conturbado no cenário externo, visto ter sido marcado pela crise argentina, pondo fim ao regime de conversibilidade e pelo atentado terrorista de 11 de setembro nos EUA. No plano interno, o país sofreu com a crise energética e todos esses fatores contribuíram para o não retorno dos capitais de curto prazo e em portfólio, como mostra o Gráfico 2. O ano de 2002 não teve comportamento muito diferente por parte do mercado financeiro. Foi quando os investidores internacionais estavam passando por um período de aversão mais intensa ao risco em decorrência de problemas associados ao mercado financeiro norte americano ${ }^{13}$. Observavam-se, então, questões específicas relativas à economia brasileira em que havia um temor de natureza política associado à possibilidade de vitória do candidato de oposição nas eleições presidenciais, com tendência a mudanças mais fortes na política econômica. Nesse cenário, a taxa de câmbio atingiu patamares recordes, situando-se ligeiramente abaixo de R \$ US\$ 4,00 em outubro. Já, a partir do momento de transição governamental, mais ainda, no início do novo governo em 2003, as incertezas do mercado financeiro começaram a dissipar-se após reiteradas mostras de continuidade da política econômica ortodoxa do governo anterior (Giambiagi, 2005).

Abre-se, também, um novo ciclo de expansão da liquidez internacional que, em grande medida, justifica a mudança no padrão da conta financeira do Brasil e de outros países emergentes (Cintra; Cagnin, 2007 e Cintra, 2006).

Com efeito, os capitais de curto prazo e em portfólio voltaram a ingressar com força na economia brasileira a partir do início de 2004, aproveitando a janela de oportunidade para auferirem ganhos de arbitragem com o diferencial de juros interno/externo. Na outra ponta, o saldo comercial, sempre crescente, fez com que o Brasil passasse a apresentar superávit em transações correntes a partir de 2003. $\mathrm{O}$ fato contribuiu para reduzir a desconfiança do mercado financeiro internacional, o que se traduziu em mais ingressos de capital (BCB, 2001, 2002, 2003).

Desde o início do plano, portanto, destacam-se dois ciclos de elevada liquidez internacional e consequente fluxo de capitais em direção à economia brasileira. O primeiro inicia-se, ainda, antes do lançamento oficial do Plano Real e vai até a sequência de crises financeiras a qual assolou as economias periféricas entre 1997 e 1999. A economia brasileira padece de um problema histórico de inadequação do sistema financeiro doméstico no que tange aos mecanismos de financiamento de longo prazo (Studart, 2005).

(13) Para uma analise mais detalhada dessa questão, ver Cintra e Cagnin (2007) e Cintra (2006). 
Essa incapacidade de fornecer financiamento de longo prazo associada aos problemas estruturais que deixam latente a restrição de divisas ao crescimento provocam, nessas economias, um comportamento reflexo aos ciclos de liquidez internacional. Significa que, havendo disponibilidade de liquidez, elas crescem; não havendo, não crescem. Seu crescimento, todavia, como reflexo da expansão da liquidez internacional, acontece quando são vulnerabilizadas e sujeitas a crises associadas ao setor externo (Resende; Amado, 2007).

Assim, se os movimentos da liquidez internacional seguirem um padrão minskyano, espera-se um movimento cíclico de profunda instabilidade nas trajetórias de crescimento nas economias de natureza periférica.

O sistema financeiro internacional dispensa às economias centrais um tratamento distinto em relação às periféricas. Enquanto aquelas são classificadas como hedge, essas são vistas como speculative/ponzi em função de sua menor capacidade relativa de gerar o influxo de divisas necessário para honrar seus compromissos externos, fator referente às características estruturais de tais economias. A maior vulnerabilidade dos países periféricos implica em menor disponibilidade de divisas para eles vis-à-vis o centro. Da mesma forma, contudo, que se analisa o financiamento para economias fechadas quando se trata do modelo de Minsky nas fases ascendentes do ciclo de liquidez internacional, vulnerabilidade e fragilidade amenizam-se e o otimismo generalizado permite a expansão do crédito, inclusive para a periferia (Resende; Amado, 2007).

Nas fases descendentes do ciclo, o otimismo é desfeito e há um racionamento de crédito assimétrico para a periferia. Verifica-se, então, um aumento da preferência pela liquidez, expresso por meio da compra de ativos estrangeiros e a consequente fuga de capitais, com agravamento da situação externa desses países.

Resende e Amado (2007) mostram que, de fato, o aumento do passivo externo líquido que corresponde ao déficit em conta-corrente do balanço de pagamentos, do Brasil, México e Argentina, está correlacionado com a elevação da liquidez internacional nos últimos trinta anos. Segundo os autores mencionados, a correlação negativa sugere a validade do argumento cepalino de que a estrutura produtiva das economias latino-americanas gera uma situação de estrangulamento externo crônico. Isso implica em uma inserção pouco competitiva das economias no mercado global, além de uma base produtiva pouco diversificada em relação às economias desenvolvidas. Assim sendo, o crescimento das economias latino-americanas tem como pré-requisito o aumento das importações em meio a uma inserção pouco competitiva das exportações. Ao longo do ciclo de expansão econômica, persiste uma tendência de deterioração da balança comercial e do saldo de transações correntes, viabilizada pelo ingresso líquido de recursos na conta financeira que ocorre nos momentos de expansão da liquidez internacional. Dessa maneira, o processo de crescimento da periferia em 
geral e da América Latina em particular reflete os ciclos de liquidez no sistema financeiro internacional de acordo com Resende e Amado (2007) ${ }^{14}$ e explicita a vulnerabilidade de tais países.

Inserido no contexto de expansão cíclica da liquidez, Plihon (1995), ao tratar a ascensão das finanças especulativas, destaca o processo de financeirização da economia e a tendência de a conta financeira cada vez mais ganhar terreno sobre as transações correntes. Suas conclusões estão baseadas em uma série de estudos para a economia francesa, mas a mesma tendência pode ser observada para diversas economias, mostrando uma tendência generalizada à financeirização da economia internacional. Em 1993, essa distribuição já se encontrava revertida, dado que as transações correntes representavam $23 \%$ e os movimentos de capitais $77 \%$ dos fluxos totais registrados. A questão havia sido destacada anteriormente quando se tratava da relação entre liberalização, globalização e financeirização. No caso específico do Brasil, o processo de financeirização do setor externo poderá ser observado no Gráfico 3 que traz o fluxo total (ingressos + remessas) do balanço de pagamentos, separado entre movimentos de capitais e transações correntes para o período de 1994 a 2009. Percebe-se caráter cíclico de expansão e contração dos movimentos de capitais na economia brasileira, agravado justamente devido a sua característica de economia periférica com os riscos aí embutidos.

Gráfico 3

Fluxo total do Balanço de Pagamentos do Brasil: 1994-2009

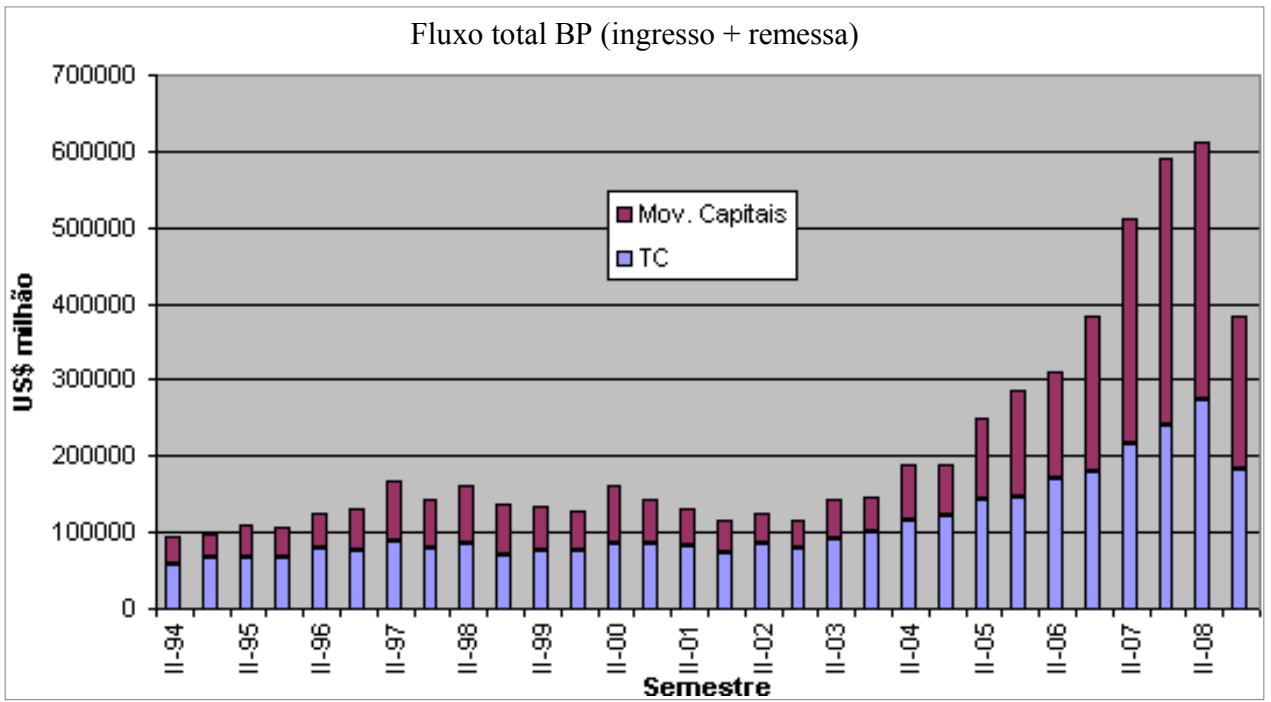

Fonte: Banco Central do Brasil - Séries Temporais.

(14) Carlos Aguiar de Medeiros (Medeiros, 2008) observa a similaridade do padrão cíclico entre os vários países da América Latina e associa esse padrão à estratégia de integração internacional de tais países como resposta ao movimento do capital internacional. 
Gráfico 4

Corrente de Comércio x Investimento Portfólio 1994-2009

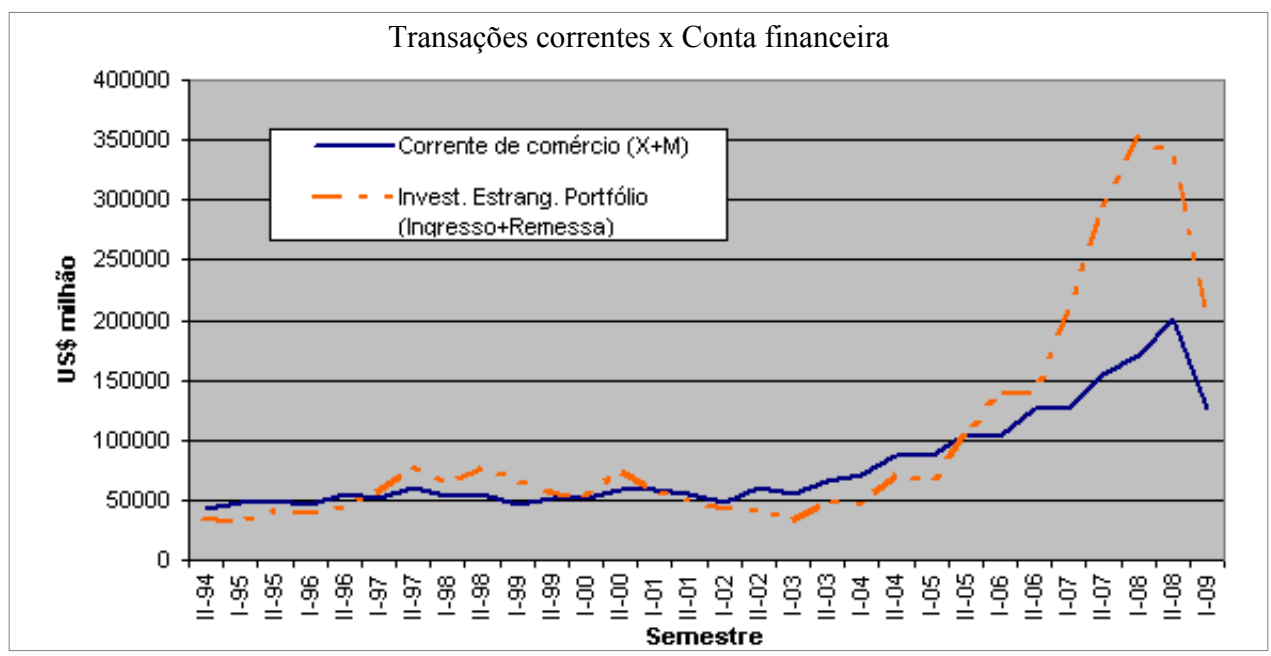

Fonte: Banco Central do Brasil - Séries Temporais.

Por seu turno, o Gráfico 4 ilustra, para o mesmo período, o comportamento das duas rubricas mais representativas dessas duas esferas do balanço de pagamentos: a balança comercial pelo lado das transações correntes e o investimento em portfólio pelo lado da conta financeira. Ambas foram analisadas em seu fluxo total (ingresso mais remessas) ao longo do ano. É fácil perceber que, apesar do relevante incremento da corrente de comércio ocorrido a partir de 2002, o investimento em portfólio cresceu de forma mais acelerada ainda a partir de 2003, terminando por ultrapassar a primeira em 2005.

\section{Considerações finais}

$\mathrm{O}$ artigo procurou usar o caso da economia brasileira para ilustrar a posição reflexa e frágil das economias periféricas no processo de financeirização destacado por Plihon (1995) que tende a agravar os efeitos dos ciclos de liquidez na economia real, em especial nas periféricas. Resgatando Minsky (1986), as crises financeiras são eventos recorrentes na economia, tendo em vista que o sistema financeiro é endogenamente instável. Não só é instável como tende a fragilizar-se ao longo da fase ascendente do ciclo econômico. Isso não se deve a acidentes nem a erros de política econômica, mas resulta do funcionamento normal da economia.

Os bancos são, em sua essência, unidades speculative, dado que captam depósitos à vista e empréstimos de curto prazo em uma ponta e concedem financiamentos de prazo mais longo em outra. Agindo assim, nos momentos de excessivo otimismo, o nível subjetivamente aceitável de endividamento dilata-se, 
tornando mais frágil a estrutura financeira. Em outras palavras, existe uma tendência a investir-se cada vez mais na economia durante os momentos de prosperidade e esse investimento será cada vez mais viabilizado por projetos de financiamento mais e mais arriscados, o que implica em maior susceptibilidade às crises financeiras.

Para Minsky (1982b), “...the financial structure becomes more susceptible to a financial crisis even as businessmen and bankers extrapolate success in fulfilling financial commitments into diminished protection against a financial crisis" (p. 26)

Essa susceptibilidade à crise é decorrente da subjetividade dos empresários e bancos acerca do nível de endividamento considerado minimamente seguro e da capacidade de criação de liquidez por parte dos bancos. Os bancos, não obstante, sempre buscam novas oportunidades de lucro, o que resulta em inovações nas práticas financeiras com a consequente expansão da liquidez e agravamento da fragilidade. Esses fatores alimentam a fase ascensionista da economia (Mollo, 1988).

Dado que o processo de criação de meios de financiamento à atividade produtiva é endógeno, no período de boom, o investimento estará garantido enquanto estiverem abertos os canais de financiamento. A situação reverte-se na medida em que a subjetividade do comportamento dos agentes provoca uma retração da oferta de financiamento, o que termina por traduzir-se em elevação da taxa de juros. Reversão de expectativas que, por seu turno, ocorre justamente em função do fator incerteza não probabilizável, abordado em Keynes (1985). Dessa forma, os ciclos de euforia e frustração financeira/econômica repetem-se em seguida, como originalmente enfatizado por Minsky (1986).

Observou-se o comportamento do índice de fragilidade externa da economia brasileira em dois períodos pós-real (âncora cambial e câmbio flutuante) e que se preserva seu comportamento cíclico. Mostra-se, assim, que o ciclo reflexo e a questão principal da fragilidade externa de uma economia periférica, como a brasileira, não estão associados ao regime cambial e, sim, a problemas estruturais que dizem respeito tanto ao setor real quanto à dinâmica monetária e financeira.

Esses elementos conduzem conjuntamente à conclusão de que, em que pese o forte incremento do saldo comercial brasileiro nos últimos anos, atuando no sentido de diminuir a fragilidade externa da economia, o aumento no movimento de capitais voláteis foi ainda mais significativo, mais do que exaurindo os ganhos advindos do comércio exterior. Assim sendo, a economia, ao assumir uma postura mais speculative, vem caminhando para aumentar sua fragilidade nos termos propostos por Minsky. Os saldos positivos com o comércio exterior, todavia, 
foram registrados com base na ampliação participativa dos produtos primários na pauta de exportações. Mostrará, assim, um reforço da posição tradicional do Brasil na divisão internacional do trabalho e irá colocá-lo em uma posição frágil, também, sob o ponto de vista de sua estrutura do balanço de pagamentos na esfera real, aprofundando os problemas estruturais do comércio internacional e da relação centro/periferia.

A reação do Brasil à crise financeira internacional, todavia, levará a crer que o arcabouço teórico aqui explorado não faz muito sentido. A crise financeira internacional promoveu o resgate das ideias de Minsky (1982, 1982b, 1986), inclusive pela ortodoxia, para mostrar como se deu a gestação e eclosão da mesma. A liberalização levada ao extremo e o processo de profunda desregulamentação dos mercados foram elementos propulsores do ciclo de natureza minskyana e da crise que acompanhou tal reversão.

No caso da economia brasileira, alguns fatores contribuíram para a minimização de seus impactos. Primeiro, como observado no artigo, o Brasil vinha acumulando reservas internacionais de forma sistemática. Isso, apesar de ser, em parte, contrabalançado pelos movimentos de capitais, deu alguma segurança e independência ao país no momento da crise e permitiu que ele se contrapusesse de forma consistente aos movimentos mais intensos dos capitais internacionais. Significa que a política cambial não foi deixada apenas ao livre arbítrio do mercado. Houve a intervenção exógena do Estado ao mesmo tempo que existiam mecanismos para isso (acúmulo de reservas). Em contrapartida, no caso da crise específica, os juros os quais inviabilizaram o crescimento historicamente estavam em um patamar que, se caíssem, não ocasionariam sobressaltos no mercado. Ao mesmo tempo, o sistema bancário brasileiro, que sempre se mostrou absolutamente disfuncional e esteve apenas envolvido em operações de tesouraria, tendo apenas uma participação marginal na extensão de crédito, também não foi atingido pela crise, exatamente em função dessas características. Inversamente, os bancos públicos, que sempre foram execrados pela vertente liberal, tiveram um papel fundamental na manutenção da liquidez no sistema e na manutenção do nível de atividade. O fato de o Brasil estar em uma posição cuja dinâmica de mercado não se encontrava em estado puro e havia instrumentos construídos ou mantidos de intervenção do Estado na economia, permitiu que os efeitos da crise fossem minimizados na economia brasileira. Nenhum desses elementos, contudo, reduz o poder explicativo do modelo exposto, porém mostra a importância de se criar colchões de proteção para a vulnerabilidade endógena das economias periféricas. Mostra, também, que tais colchões passam por elementos exógenos à lógica de mercado os quais só podem ser conduzidos pelo Estado. 
Liberalização, vulnerabilidade financeira e instabilidade: algumas considerações sobre a economia brasileira

\section{Referências bibliográficas}

ARESTIS, P.; GLICKMAN, M., Financial crisis in Southeast Ásia: dispelling illusion the Minskyan way. Cambridge Journal of Economics, v. 26, p. 237-260, 2002.

BARHRY, T. R.; PORCILE, G. Os ciclos de endividamento da economia brasileira no período 1968-1999. Revista de Economia Contemporânea, Rio de Janeiro, v. 8, n. 1, p. 532, 2004.

BCB. Boletim Análise do Mercado de Câmbio. Disponível em: http://www.bcb.gov.br/. Acesso em: 5 ago. 2003.

Boletim Análise do Mercado de Câmbio. Disponível em: http://www.bcb.gov.br/. Acesso em: 12 ago. 2002.

Boletim Análise do Mercado de Câmbio. Disponível em: http://www.bcb.gov.br/. Acesso em: 15 ago. 2001.

Boletim Análise do Mercado de Câmbio. Disponível em: http://www.bcb.gov.br/. Acesso em: 20 ago. 2000.

Boletim Análise do Mercado de Câmbio. Disponível em: http://www.bcb.gov.br/. Acesso em: 29 ago. 1999.

BELLUZO, L. G. O declínio de Bretton Woods e a emergência dos mercados globalizados. Economia e Sociedade, Campinas, n.4, p. 11-20, 1995.

; CARNEIRO, R. O mito da conversibilidade. Revista de Economia Política, v. 24, n. 2, p. 218-222, abr./jun. 2004.

CHESNAIS, F. Le capital de placement: accumulation, internationalization, effets économiques et politiques. In: (Ed.). Paris: La Finance Mondialisée: Racines Sociales et Politiques, Configuration, Consequences Découverte, 2004.

. A mundialização do capital. São Paulo: Xamã, 1998.

. Mundialização financeira. São Paulo: Xamã, 1996.

CHICK, V. The evolution of the banking system and the theory of Saving, investment and interest. Econommies et Societes, v. 20, Serie Monnaie et Production, 1986.

CINTRA, M. A. A dinâmica da economia mundial no início do século XXI. São Paulo: Fundação Maurício Grabois, 2006. (Coleção Princípios, n. 85) 2006. Disponível em: http://www.fmauriciograbois.org.br/portal/cdm/revista.int.php?id_sessao=50\&id_publicacao $=195 \&$ id_indice $=1630$.

; CAGNIN, R. Euforia e pessimismo: os ciclos de ativos, de crédito e de investimento da economia americana após 1982. Novos Estudos Cebrap, v. 79, 2007.

CUNHA, A. M. Estratégias periféricas sessenta anos depois do acordo de Bretton Woods. Revista de Economia Política, v. 26, n. 4, p. 483-501, out./dez. 2006. 
DOOLEY, M. P. et al. An essay on the revived Bretton Woods System. Cambridge, Mass.: National Bureau of Economic Research, 2003. (NBER Working Paper, n. 9971).

DOW, S. C. The regional composition of the money multiplier process. Scottish Journal of Political Economy, v. 29, n. 1, 1982.

EDISON, H. et al. Capital account liberalization and economic performance: a review of the literature. Washington, DC: International Monetary Fund, 2002. (IMF Working Paper, $02 / 120)$.

EPSTEIN, G. A. Financialization and the world economy. Cheltenham, UD/ Northampton, MA, USA: Edward Elgar, 2005.

GARCIA, M. G. P. Dívida externa em real. Disponível em: http://www.econ.pucrio.br/Mgarcia/Artigos/Artigos Valor/051007 DívidaExternaemReal.pdf. Acesso em: 28 ago. 2005.

GIAMBIAGI, F. Rompendo com a ruptura: o governo Lula (2003-2004). In:

VILLELA, A. (Org.). Economia brasileira contemporânea. Rio de Janeiro: Editora Elsevier, 2005.

GUTTMANN, R. Les mutations du capital financier. In: CHESNAIS, F. (Coord.). $L a$ mondialisation financière: genèse, coût et enjeux. Paris: Syros, 1996.

IMF. World Economic Outlook. Washington, DC: International Monetary Fund, Oct. 2001.

KEYNES, J. M. Preparation. In: THE COLLECTED writings of John Maynard Keynes, v. XIII. Cambridge, Mass.: Macmillan, 1973.

. A treatise on money: the pure theory of money. In: THE COLLECTED writings of John Maynard Keynes, v. V. Cambridge, Mass.: Macmillan, 1971. The general theory, Part I.

1937.

. The general theory of employment. Quarterly Journal of Economics, n. 51, Feb. [1936] 1985.

A teoria geral do emprego, do juro e da moeda. São Paulo: Nova Cultural,

KNIGHT, F. H. Risk, uncertainty and profit. London: London School of Economics, 1933.

KREGEL, J. Minsky and Asia: 'it' did happen again. Paper presented at the International Conference on The Legacy of Hyman Minsky. Bergamo, Italy: University of Bergamo. Department of Economics, 10-12 Dec. 1998.

KINDLEBERGER C. H. Manias, pânicos e crashes. 3. ed. Rio de Janeiro: Nova Fronteira, 2000.

LÓPEZ, J. Mexico's crisis: financial modernization and financial fragility. BNL Quarterly Review, n. 201, Jun. 1997. 
MEDEIROS, C. A. Financial dependency and growth cycles in Latin American countries. Journal of Post Keynesian Economics, v. 31, n. 1, 2008.

MINSKY, H. P. Integração financeira e política monetária. Economia e Sociedade, n. 3, p. 21-36, dez. 1994.

. Stabilizing an unstable economy. New Haven: Yale University Press, 1986.

. Inflation, recession and economic policy. New York: M. E. Sharpe, 1982.

. The financial instability hypothesis: capitalist processes and the behavior of the economy. In: KINDLEBERGER; LAFFARGUE (Org.). Financial crises. Cambridge, $1982 \mathrm{~b}$.

MOLLO, M. L. R. Instabilidade do capitalismo, incerteza e o papel das autoridades monetárias: uma leitura de Minsky. Revista de Economia Política, São Paulo, v. 8, n. 1, p. 100-123, jan./mar. 1988 .

PAULA, L. F. R.; ALVES JR., A. J. External financial fragility and the 1998-1999 Brazilian currency crisis. Journal of Post Keynesian Economics, Armonk, v. 22, n. 4, pp. p. 589-617, Summer 2000.

PLIHON, D. A ascensão das finanças especulativas. Economia e Sociedade, Campinas, n. 5, p. 61-78, dez. 1995.

PRASAD, E.; ROGOFF, K. et al. Effects of financial globalization on developing countries: some empirical evidence. Washington, DC: IMF, 2003. Disponível em: http://www.imf.org/external/np/res/docs/2003/031703.pdf

PRATES, D. M. As assimetrias do sistema monetário e financeiro internacional. Revista de Economia Contemporânea, Rio de Janeiro, v. 9, n. 2, p. 263-288, maio/ago. 2005.

RESENDE, M. F. C.; AMADO, A. M. Liquidez internacional e ciclo reflexo: algumas observações para a América Latina. Revista de Economia Política, São Paulo, v. 27, n. 1, jan./mar. 2007.

STUDART, R. Financiamento do desenvolvimento. In: GIAMBIAGI, F.; VILLELA, A. (Org.). Economia brasileira contemporânea. Rio de Janeiro: Editora Elsevier, 2005.

UNCTAD - United Nations Conference on Trade and Development. Trade and Development Report, 1998. New York; Geneva: United Nations, 1998.

Velloso, J. P. R.; ALBUQUeRQUe, R. C. Cinco décadas de questão social e os grandes desafios do crescimento sustentado. Rio de Janeiro: José Olympio Editora, 2005.

WYPLOSZ, C. Financial restraints and liberalization in postwar Europe. In: CAPRIO, G.; HONOHAN, P.; STIGLITZ, J. (Org). Financial liberalization, how far, how fast. Cambridge: Cambridge University Press, 2001. 